\title{
A note on the role of olfaction in taste aversion learning
}

\author{
ROBERT ADER \\ Department of Psychiatry, University of Rochester School of Medicine and Dentistry, \\ Rochester, New York 14642
}

\begin{abstract}
A taste aversion was induced by the single or multiple pairing of saccharin and methotrexate. In one experiment the presence of saccharin in the environment of condtioned animals prior to the test trials resulted in an attenuation of the aversion, that is, facilitated extinction of the conditioned response. In a second experiment the consumption of plain water by conditioned animals was significantly reduced when animals were tested in the presence of other animals that were provided with saccharin, the CS solution. The data suggest that primary stimulus generalization in the form of olfactory cues can influence the manifestation of taste aversion behavior by decreasing the magnitude of the avoidance response or by decreasing the consumption of fluid by control animals.
\end{abstract}

The rat is capable of acquiring an aversion to a novel, distinctively flavored drinking solution on the basis of a single pairing of the distinctive taste with any of several toxic agents. The rat's ability to form an association between an odor and toxicosis is less certain. Several reports (Domjan, 1973; Garcia \& Koelling, 1967; Lorder, Kenfield, \& Braun, 1970; Lovett, Goodchild, \& Booth, 1968; Supak, Macrides, \& Chorover, 1971; Taukulis, 1974) suggest that odor aversions can be conditioned or that the rat can use olfactory cues in acquiring a taste aversion. Other studies (Hankins, Garcia, \& Rusiniak, 1973; Hankins, Rusiniak, \& Garcia, 1976; Hargrave \& Bolles, 1971) suggest that olfactory cues exert little or no influence on taste aversions and are relatively ineffective stimuli for inducing avoidance responses based on physiologic disruptions. A generalization based on the data presently available would suggest that under appropriate circumstances the rat is capable of associating olfactory cues with internal consequences but that such learning does not appear to be as efficient as that produced by the pairing of gustatory and visceral stimulation. That is, acquisition of odor aversion may require more than a single conditioning trial and relatively short CS-US intervals.

The present data will not resolve the issue of the extent to which the rat uses olfactory and gustatory stimuli to avoid potentially noxious consequences. However, the contention that "odor cues have relatively little functional value in the acquisition of food aversions by the laboratory rat" (Hankins et al., 1976, p. 345) seems somewhat extreme in view of all the published literature, and the present note describes additional observations implicating olfaction in the

This research was supported by USPHS Grant HD-09977 from the National Institute for Child Health and Human Development. manifestation of taste aversion behavior. As such, these observations are relevant to the design and execution of studies of taste aversion learning.

\section{METHOD}

Data concerning the role of olfaction in taste aversion learning were extracted from two experiments designed for a different purpose and involving several differentially treated groups of animals. Only those groups relevant for examining the influence of olfaction on the avoidance behavior will be described here.

Both experiments used male Charles River (CD) rats approximately 3 months of age. The animals were individually caged under an LD12:12 light-dark schedule and provided with food ad lib. Water was provided for a decreasing amount of time each day until the total daily drinking period was reduced to $15 \mathrm{~min}$, beginning at approximately 9:30 a.m., $3.5 \mathrm{~h}$ after light onset. After 5 days under this regimen, training was initiated.

In Experiment 1, all animals were provided with a $.1 \%$ saccharin drinking solution instead of plain tap water for $15 \mathrm{~min}$. Immediately thereafter the animals were injected IP with $25 \mathrm{mg} / \mathrm{kg}$ methotrexate (MTX). The single pairing of saccharin and MTX was followed by 4 days during which plain water was provided during the 15 -min drinking period. This was followed by 2 successive days on which some animals were again provided with the saccharin drinking solution while others received plain water. This experiment was conducted in two different (but virtually identical) colony rooms. Approximately half the animals to be provided with saccharin and half the animals to be provided with plain water (SACCH PRESENT) were housed in a room in which the solution of saccharin was prepared late on the day preceding the test trials and remained in that colony room until after the second test period. For the remaining animals (SACCH ABSENT), saccharin was not present in the colony room except during the two 15 -min test periods.

In Experiment 2, conditioned animals were given three trials on which the consumption of a $.1 \%$ saccharin solution was followed by the IP injection of $50 \mathrm{mg} / \mathrm{kg}$ MTX. A nonconditioned group was injected with MTX but received no saccharin until the two test trials, which, in this experiment, were administered 3 and 5 days after the last conditioning trial. Conditioned animals were provided with saccharin or plain water on the test days. Of those conditioned animals provided with plain water, 


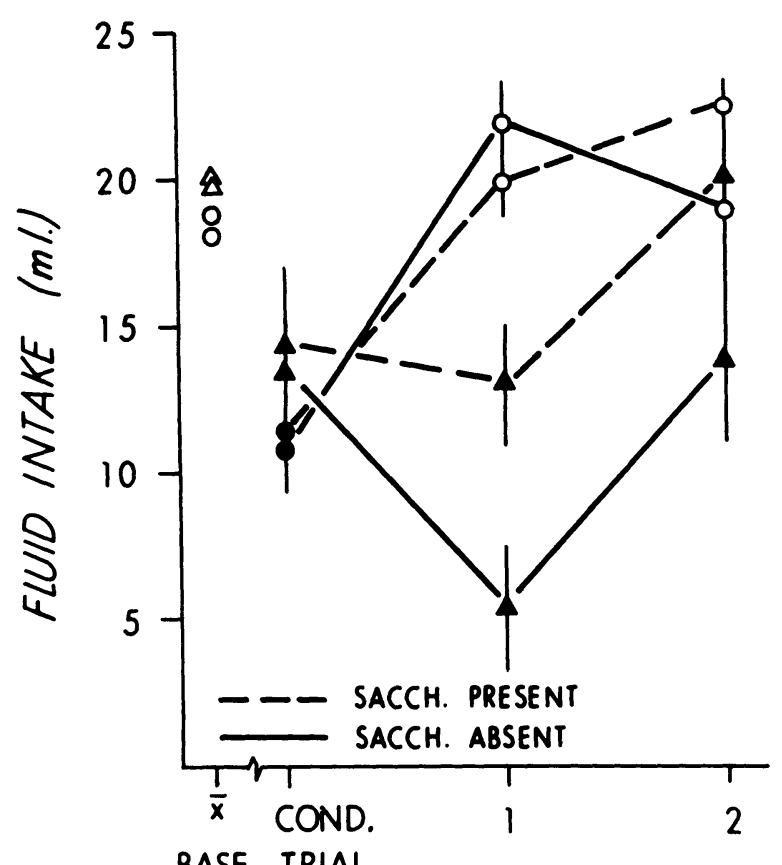

BASE. TRIAL

\section{TEST TRIAL}

Figure 1. Mean $( \pm$ SE) consumption of plain water (open symbols) and saccharin (filled symbols) for conditioned animals with and without the presence of saccharin in the environment.

some were housed in a room in which other animals were receiving saccharin (SACCH PRESENT), while others were housed in a room in which no saccharin was present (SACCH ABSENT) during the 15 -min drinking period.

\section{RESULTS AND DISCUSSION}

The results of Experiment 1 are shown in Figure 1. There was, as is usual, evidence of neophobia in response to the initial exposure to the saccharin drinking solution. Relative to the volume of saccharin consumed on the conditioning trial, animals subsequently provided with saccharin in the absence of any pretest exposure to the solution displayed an aversion to the solution (i.e., a reduction in the volume consumed). In contrast, the presence of saccharin in the immediate environment prior to testing attenuated this aversive response. Fluid consumption on the first test trial was significantly influenced by the drinking solution provided and the environment in which the solution was provided $[F(1,31)=6.16, p<.05]$. Animals in the SACCH PRESENT group did drink less saccharin than conditioned animals that were given water in that same room $(\mathrm{t}=2.88, \mathrm{p}<.01)$, but they consumed significantly more of the saccharin solution than the SACCH ABSENT group $(t=2.53, p<.01)$. There were no significant differences on the second test trial $(\mathrm{F}<1)$.

On the basis of these differences, it might have been expected that the SACCH PRESENT animals provided with plain water but tested in the presence of other animals that were provided with the saccharin solution might show some reduction in water consumption. The two conditioned groups tested with plain water, however, did not differ.

The possibility that conditioned animals provided with plain water might be influenced by the presence of saccharin in the immediate environment was examined further in Experiment 2. The examination of this possibility was actually precipitated by an overall analysis of the full study which revealed an unusually low consumption of water in a group of conditioned animals that were subsequently provided with plain water instead of saccharin on 2 test days. It was for this reason that an analysis was undertaken in which this group was divided into those that were and those that were not tested in the presence of animals that were provided with saccharin. The results are shown in Figure 2.

During the course of the three conditioning trials, the consumption of saccharin by conditioned animals was, as expected, depressed, and conditioned animals consumed significantly less saccharin than nonconditioned animals on the two test trials. Conditioned animals that were provided with plain water in the presence of other animals provided with saccharin, the SACCH PRESENT (C-SP) group, showed an intake of water which was equivalent to the reduced consumption of saccharin in conditioned (C) animals, while a comparable group tested in the absence of saccharin in the environment (C-SA) showed an intake of water that was equivalent to baseline levels and to the consumption of saccharin by nonconditioned (NC) animals. The difference between the water consumption of the SACCH ABSENT and SACCH PRESENT groups was highly significant $(T=9.06, p<.001)$.

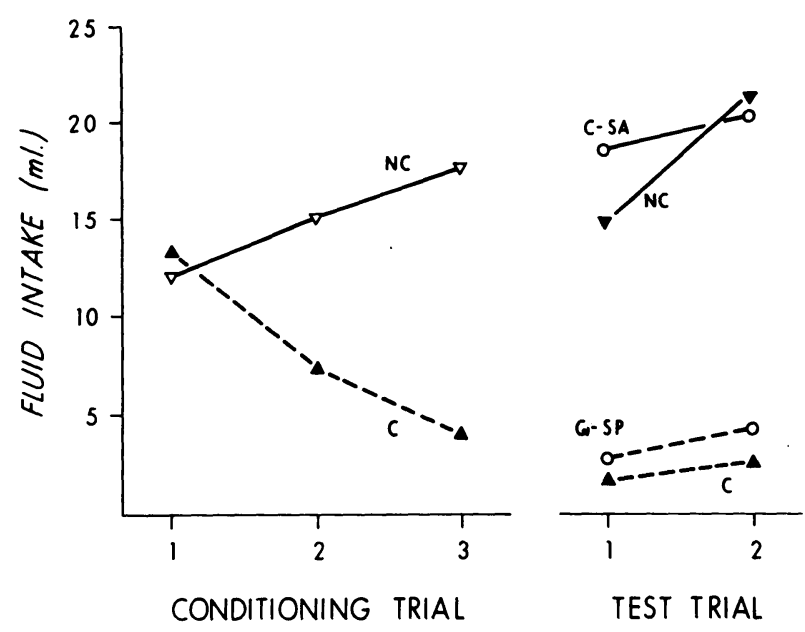

Figure 2. Mean consumption of plain water (open symbols) and saccharin (filled symbols) in conditioned (C) and nonconditioned (NC) animals during the course of three training trials and during two test trials when conditioned animals provided with plain water were tested in the presence (SP) or absence (SA) of saccharin in the environment. 
If one considers the differences between Experiments 1 and 2 (e.g., the dose of MTX, the number of conditioning trials, the interval between test trials), the discrepancy in results yielded by the conditioned animals that were provided with plain water is not especially surprising. Taken together, the results of these experiments indicate that the mere presence (i.e., presumably, the odor) of saccharin in the environment of animals being tested for the development of a taste aversion to saccharin is potentially able to attenuate the conditioned response. This can result from a diminution in the magnitude of the avoidance response in conditioned animals (as in Experiment 1) or an artifactual reduction in the water intake of conditioned animals that are serving as a control or comparison group. It may be conjectured that the former instance is more likely to influence the acquisition of a taste aversion under conditions that are less than optimal for inducing a taste aversion, while the latter possibility could act as a contaminant in studies that produce strong aversions to the CS solusion.

As Hankins et al. (1976) point out, "The functional roles of odor and taste cues emanating from a flavored fluid are difficult to distinguish in the intact animal because of the intimate relationship between the receptor systems and their interconnecting passageways" (p. 355). Under the conditions of Experiment 1, then, the unreinforced presence of the saccharin solution in the environment of conditioned animals could be acting to facilitate extinction of the conditioned taste aversion. Similarly, primary stimulus generalization can be invoked to account for the suppression of drinking behavior in well-conditioned animals that are provided with water in the presence of saccharin-as was the case in Experiment 2.

The literature indicates that olfaction is not necessary for the acquisition of a conditioned taste aversion. Odor aversions can be established, but these are apparently weaker than taste aversions and necessitate relatively short intervals between odor stimulation and illness or other internal changes. Be that as it may, the present data suggest that olfaction can exert some influence on performance in a conditioned taste aversion paradigm. From a purely methodological point of view, the possibility of some generalization from taste to odor and from odor to taste should, therefore, be considered in the execution of studies of taste aversion learning.

\section{REFERENCES}

Domjan, M. Role of ingestion in odor-toxicosis learning in the rat. Journal of Comparative and Physiological Psychology, 1973, 84, 507-521.

Garcia, J., \& Koelling, P. A. A comparison of aversions induced by $\mathrm{x}$-rays, toxins, and drugs in the rat. Radiation Research (Suppl.), 1967, 7, 439-450.

Hankins, W. G., Garcia, J., \& Rusiniak, K. W. Dissociation of odor and taste in baitshyness. Behavioral Biology, 1973, 8 , 407-419.

Hankins, W. G., Rusiniak, K. W., \& Garcia, J. Dissociation of odor and taste in shock-avoidance learning. Behavioral Biology, 1976, 18, 345-358.

Hargrave, G. E., \& Bolles, R. C. Rat's aversion to flavors following induced illness. Psychonomic Science, 1971, 23, 91-92.

Lorden, J. F., Kenfield, M., \& Braun, J. J. Response suppression to odors paired with toxicosis. Learning and Motivation. 1970, 1, 391-400.

LovetT, D., Goodchild, P., \& Booth, D. A. Depression of intake of nutrient by association of its odor with effects of insulin. Psychonomic Science, 1968, 11, 27-28.

Supak, T., Macrides, F., \& ChORover, S. The baitshyness effect extended to olfactory discrimination. Communications in Behavioral Biology, 1971, 5, 321-324.

TAUKULIS, H. K. Odor aversions produced over long CS-US delays. Behavioral Biology, 1974, 10. 505-510.

(Received for publication July 12, 1977.) 